\title{
"Comparative Study of Ultrasonic Placental Grading in Hypertensive Disorder in Pregnancy with Normal Pregnancy"
}

\author{
Dr. Anubha Vidyarthi ${ }^{1}$, Associate Professor Dept. Of OBGY, RIMS \\ Dr. Atima Bharti ${ }^{2}$, Associate Professor Dept. Of OBGY, RIMS \\ Dr. Suresh Kumar Toppo ${ }^{3}$, Associate Professor Dept. Of Radiology, RIMS \\ Dr. Santwana Kumari ${ }^{4}$, Post graduate Student
}

\begin{abstract}
Aim: To compare ultrasonic placental grading in hypertension in pregnancy with normotensive pregnancy and correlate with foetal outcome.

Material And Method: In this prospective study 200 pregnant patients were selected from indoor and outdoor Dept. of Obstetrics \& Gynaecology. 100 pregnant patients with pre-eclampsia were selected as study group and 100 normotensive pregnant patients as control group.

Result: In the study group 3\%, 54\% and 43\% women had placental grades I, II \& III respectively as against $8 \%, 61 \%$ and $31 \%$ of the control group women respectively. Preterm delivery <37 weeks gestational age was $28 \%$ in study group and $15 \%$ in control group. However grade III changes in $<37$ weeks gestational age in study group was $23.3 \%$ and $9.7 \%$ in control group. In $>37$ weeks gestational age grade III placental changes was $76.7 \%$ in study group and $90.3 \%$ in control group. Spontaneous delivery was higher in control group $71 \%$ compared to study group 50\% which is statistically significant. Induced delivery and caesarean section was more in study group compared to control group. Birth asphyxia was observed in all placental grades in study group.

Conclusion: Earlier knowledge of placental grade can decrease the risk of perinatal death by timely intervention. It can also predict pregnancy induced hypertension so proper intervention can be made.
\end{abstract}

\section{Introduction}

Hypertensive disorder of pregnancy affects about 5-8\% of all pregnant women worldwide [1]. The incidence of pregnancy induced hypertension $(\mathrm{PIH})$ in the world varies in developing countries, from around $7 \%$ in Zimbabwe to around $0.81 \%$ in Columbia. In rural India the incidence is $10 \%$ [2]. Hypertension in pregnancy contributes significantly to maternal \& perinatal morbidity and mortality. The relationship between placental morphology function and foetal outcome has been the subject of study for many years. Placenta is an important foetal organ which is an intermediate link between the fetus and the mother. Owing to the delicate and important nature of the placenta, it is sometimes referred to as the "mirror of the perinatal period which has not been sufficiently polished" $[3,4]$.

Proper functioning of the placenta is important for proper growth and development of the foetus in utero. Placenta being a foetal organ shows the same stress and strain, to which the foetus is exposed. Thus any disease process affecting the mother and foetus has a great impact on placenta and vice versa. Morphology of placenta varies during its short life span. Alteration in placenta as part of "ageing" phenomena are probably a part of maturation process and goes hand in hand with continued growth of placenta. The well being of the foetus is affected by many factors but a healthy placenta is the single most important factor in producing a healthy baby $[5,6]$. There is a widely and tenaciously held belief that during course of normal pregnancy the placenta progressively ages and that the term placenta is in verge of a decline into morphological and functional senescence [7]. Various complications in pregnancy have been correlated with specific micro and macroscopic placental changes. Compromised placental perfusion from uterine vasospasm almost certainly a major culprit in the genesis of increased perinatal morbidity and mortality [8] associated with pregnancy induced or pregnancy aggravated hypertension [9].

Evolution of Ultrasonography has been very useful in Obstetrics and has found application in placental studies [10]. Sonography remains the imaging modality of choice for evaluation of the placenta. It is an important part of obstetrical evaluation of pregnancy. With grey scale Ultrasonography it is possible to identify changes in placental anatomy which formally have been recognized only by examination of the placenta after delivery. By serial ultrasound examination these changes can be detected as they occur, since placenta is a foetal organ it seems logical that it should mature in fashion similar to that of other foetal organ system. In order to categorize the phase of maturation of placenta Grannum \& associates classified ultrasonic variations in placental appearance occurring during gestation and then to correlate these findings with an index of foetal lung maturity,

DOI: $10.9790 / 0853-1605062530 \quad$ ww.iosrjournals.org $25 \mid$ Page


the lecithin/sphingomyelin ratio [11]. The advent of antenatal detection of foetal pulmonary maturity by measurement of $\mathrm{L} / \mathrm{S}$ ratio in amniotic fluid has resulted in a significant reduction in both perinatal morbidity \& mortality. Unfortunately this test requires the invasive procedure of amniocentesis which is sometimes difficult or hazardous.

Ultrasonography provides a non invasive technique for the evaluation of foetal gestational maturity. In 1979 Grannum and associates described a method of classifying and grading placental maturity as the pregnancy advances based on ultrasonic evaluation of placental textural changes in vivo placenta [12]. The authors demonstrated a good correlation between maturational changes in the placenta as seen by ultrasound and the foetal pulmonary maturity as determined by L/S ratio. Petrucha and associates confirmed Grannum and associates finding, reported $100 \%$ correlation between L/S ratio and grade III placenta [13]. Quinlan and Cruz reported 3 cases of grade III Placenta with immature L/S ratio [14]. The present study was undertaken to study the ultrasound placental grading in pregnancy complicated with hypertension and compare it with normotensive pregnancy.

\section{Material \& Method}

Present study was conducted in the department of Obstetrics \& Gynaecology in Rajendra Institute of Medical Sciences, Ranchi. 200 patients were selected, 100 pregnant patients with preeclampsia as study group and 100 normotensive pregnant women as control.

Inclusion criteria

a) Control group:

1. Pregnant women in third trimester

2. Blood pressure $<140 / 90 \mathrm{~mm}$ of $\mathrm{Hg}$

3. No medical disorder

4. Singleton pregnancy

5. Vertex presentation

b) Study group:

1. Pregnant women in third trimester

2. $\mathrm{BP}>140 / 90 \mathrm{~mm}$ of $\mathrm{Hg}$

3. Singleton pregnancy

4. Vertex presentation

Pregnant women with other medical disorders, multiple pregnancy and abnormal presentation were excluded in both study and control group. Detailed history with general physical and obstetrics examination was done. Ultrasonic placental grading was noted in both control and study group. Outcome was studied in terms of placental grading, foetal maturity, perinatal morbidity and mortality and birth weight of the baby. Results were compared using chi-square test of significance. The student " $\mathrm{t}$ " test was used to determine whether there was a statistical difference between two groups in the parameters measured.

\section{Result \& Observation}

The maturational changes of placenta occurs in three basic anatomic areas-

1. Amnion chorion plate

2. Placental body

3. Basal layers.

Changes may not occur in sequential fashion and may be accelerated in hypertensive disease.

Grading of the placenta according to the criteria described by Grannum et al.

Grade 0: No significant changes within the placenta.

- The placenta represents the baseline condition.

- Remains homogenous throughout.

- There is no calcification within the body.

- The amnion Chorion plate is intact without undulation

Grade I: One major change within the placental body

- Echogenic densities (2-4mm) developed within the body of the placenta

- These echoes are high amplitude, bright white and linear or comma shaped.

- The amnion chorion plate may show subtle undulations. 
- Approximately $42 \%$ of placenta will show grade 1 changes from 31 - 36 weeks, these decreases to $37.4 \%$ by term.

- Grade 1 placenta is uncommon after 42 weeks of gestation.

- The chances of foetal lung maturity as measured by L/S ratio ranges from $48-68 \%$.

Grade II: Two major changes within the placenta

- The basal calcification occurs in a linear fashion along the junction of placenta and deciduas.

- The chorionic plate shows marked indentations that don't reach the basal plate.

- $19 \%$ of placenta shows grade II changes by $31-36$ weeks. This percentage increases to $30.6 \%$ by term.

- The chances of foetal lung maturity ranges between $69-91 \%$. There may be premature onset of to grade II changes in hypertensive disease of pregnancy.

\section{Grade III}

- The chorio amniotic plates develops multiple indentations extending to the basal layer.

- The inter-cotyledonary septa calcify producing eclipsing or shadowing of returning "Echo information". This creates apparent sonolucent or echo poor areas within the placental body giving a swiss-cheese pattern.

- $\quad$ Between 31 \& 36 weeks $9 \%$ of placenta show grade II changes which increases to $31.9 \%$ by term.

- Foetal lung maturity ranges from $95 \%$ of cases where there is no associated medical disease to $99 \%$ of chances of lung maturity where there are associated medical problems such as diabetes and hypertension.

- Both grade II and grade III placenta are found with increase incidence in the post mature foetus.

- When grade III changes are seen prior to 31 weeks of gestation hypertension of pregnancy or foetal growth restriction are more common

\section{Table - IPlacental grading in PIH and normotensive pregnancy}

In the study group 3\%, 54\% and $43 \%$ women had placental grade I, II \& III respectively as against $8 \%$, $61 \%$ and $31 \%$ of the study group women respectively and it was found to be statistically not significant) (P $>0.05$

\section{Placental grade distribution among study and control group}

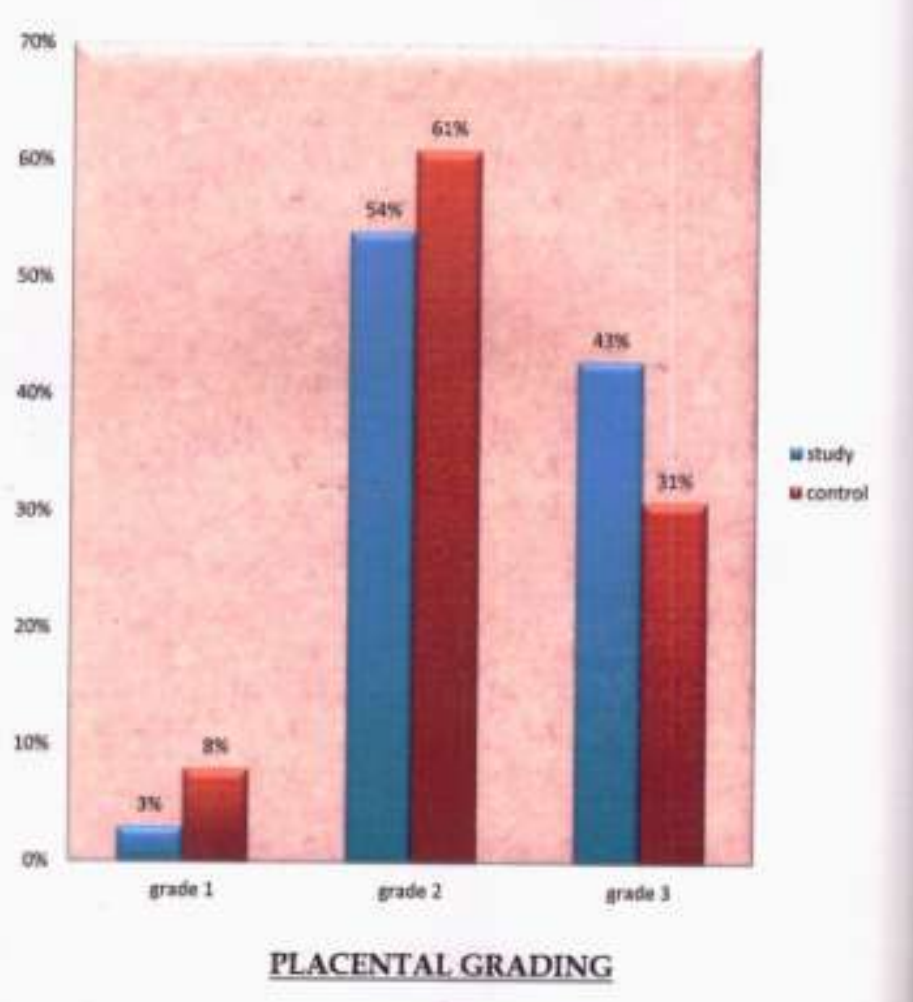

Table - II Distribution of placental grade and gestational age 


\section{Destribution of placental grade and gestational age}

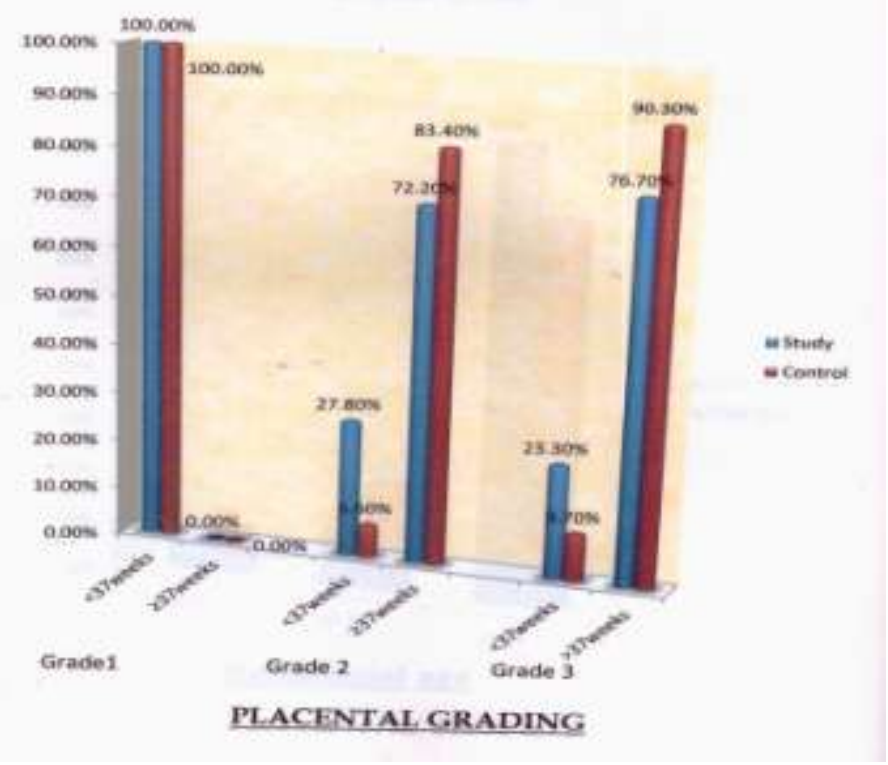

Table II depicts preterm delivery $<37$ weeks was significantly more in study group $28 \%$ compared to control group $15 \%$. P value $<0.05$ It was statistically significant. However grade III changes in $<37$ weeks and $>37$ weeks of gestation between study (23.3\%) and control group (9.7\%) was not statistically significant. P value > 0.05

Table - III Distribution of placental grade and mode of delivery

\section{Distribution of Placental grade and Mode of delivery}

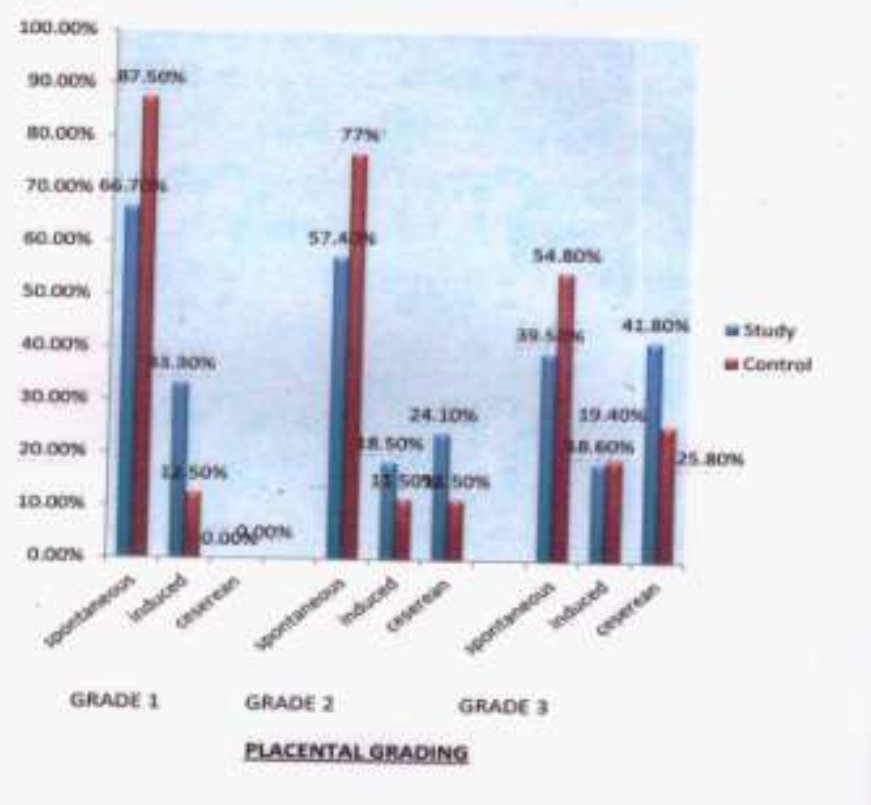

Spontaneous delivery was more in control group $71 \%$ compared to study group $50 \%$ which is statistically significant $\mathrm{p}<0.05$. Induced delivery and caesarean section were more in study group compared to control group. Induced delivery was $14 \%$ in control group compared to $19 \%$ in study group p > 0.05 Caesarean section was more in study group $31 \%$ compared to control group 15\%. There was a statistically significant difference between study group $31 \%$ and control group $15 \%$ with respect to LSCS rate $\mathrm{P}<0.05$ 
It was observed that grade III placenta, caesarean section rate was $41.8 \%$ in study group and $25.8 \%$ in control group which was not statistically significant $p>0.05$. Birth asphyxia was observed in all placental grades in study group and it was more in study group $8 \%$ compared to control group 4\%. Birth asphyxia was more with grade III placenta in study group $9.3 \%$ compared to control group $3.2 \%$ which was not statistically significant $\mathrm{p}$ $>0.05$.

\section{Discussion}

Hypertension and intrauterine growth retardation showed a strong correlation with accelerated placental maturation, whereas diabetes and $\mathrm{Rh}$ sensitization where associated with delayed maturation with placenta [15]. Detection of higher grade of placenta early in $3^{\text {rd }}$ trimester can alert the Obstetrician for close observation regarding development of PIH, IUGR, Foetal distress and Foetal maturity, as there is definite correlation of early maturation of placenta with foetal complication [16]. Premature ageing of placenta is an indicator of decline in its function and is found to be associated with increased incidence of maternal and foetal complications [16].

Maximum number of high risk cases where found due to pregnancy induced hypertension [17, 18]. In our study it was observed that in normal case grade III placenta is seen after 37 weeks of pregnancy whereas grade I \& II are mostly seen after 32 weeks. In PIH grade II \& II are seen in between $32-37$ weeks, grade I is seen at $28-32$ weeks. This result is consistent with study of Grannum et al [19].

Incidence of foetal distress was observed more with grade III placenta before 37 weeks as compared to grade I \& grade II placenta. Birth asphyxia was observed more with grade III placenta in study group 9.3\% compared to control group $3.2 \%$.

Hooper et al noted that if the placenta appeared to be grade I prior to 27 weeks, grade II prior to 32 weeks and grade III prior to 34 weeks of gestation, the pregnancy would be likely to be complicated with intrauterine growth retardation and pre-eclampsia [20]. This study is similar to our study. Thinner placenta belonged to grade III maturity [21]. Placenta maturity could be a probable cause for decline in placental thickness after 38 weeks [21]. In the present study it was concluded that other than IUGR there was no statistical significant correlation between ultrasound grading of placenta and foetal complications like feotal distress, birth asphyxia and perinatal morbidity.

\section{Conclusion}

The advancement of placenta grade was found to be associated with an increase in L/S ratio and Phosphatidylglycerol (PG) level in amniotic fluid. A mature placenta grade III identified by real time Sonography corresponded to foetal lung maturity $(\mathrm{L} / \mathrm{S} \geq=2, \mathrm{PG}>0.36 \mathrm{mg} / \mathrm{dl})$ and absence of respiratory distress syndrome in all cases. Earlier knowledge of placenta grade can decrease the risk if perinatal death by appropriate intervention and also detect pregnancy induced hypertension earlier.

\section{Bibliography}

[1]. Arshad A, Pasha W, Khattak T and Kiyani RB. Impact of pregnancy induced hypertension on birth weight of newborn at term. Journal of Rawalpindi Medical College (JRMC); 2011; 15 (2): 113-115.

[2]. Menon KMR, Devi PK, Rao BK. Postgraduate Obstetrics \& Gynaecology, $4^{\text {th }}$ edition

[3]. Machin GA, Ackerman J and Gilbert-Barness E (2000) abnormal umbilical cord coiling is associated with adverse perinatal outcome. Paediatric and development pathology, 3: 465-471.

[4]. Valsamakis G, Kanaka-Gantenbein C, Malamitsi-Puchnu A and Mastorkas G (2006) causes of intrauterine growth restriction and postnatal development of the metabolic syndrome. Annuals of the New York academy of sciences, 1092: 138-147.

[5]. Van Den Broek, N-Ntonya, C-Kayira, E-White et al 2005 preterm birth in rural Malawi, high incidence in ultrasound dated population. Human reproduction, 20: 3235-3237.

[6]. Kliman HJ 1997 behind every healthy baby is a healthy placenta. Reproductive and placenta research unit, PPI

[7]. Ruth A Petrucha, Lawrence D Platt; relationship of placental grade to gestational grade Am J. Obstet Gynaecol-144, 733-1982.

[8]. Robert M Patterson, Robert M Hyashi, Dora Cavazos LVN. Ultrasonographically observed early placental maturation and perinatal outcome. Am J Obstet Gynaecol-147, 773-1983.

[9]. T Marine Obstet Gynaecol Clin N AM 31 (2004) 171-200.

[10]. Appiah PK (2009) relationship between placenta, umbilical cord and perinatal outcome. Available from Knust. edu. gh.

[11]. Peter A Grannuma, Rechard L Bekowitz, John C Hobbins, the placenta radiologic clinics of north American. 20 (2); 81 ; 1982.

[12]. Peter A Grannuma, Rechard L Bekowitz, John C Hobbins. The ultrasonic changes in the maturing placenta and the relation to foetal pulmonic maturity. Am J. Obstet Gynaecol-133, 915-1979.

[13]. Ruth A Petrucha, SH Colde, Lawrence D Platt; Real time ultrasound of the placenta in assessment of foetal pulmonic maturity. Am J Obstet \& Gynaecol-142, 463-1982 (a).

[14]. Quinol RW; A C Curz, W C Buhi, M Martin RN. Changes in placental ultrasonic appearance II pathological significane of grade III placental changes AM J Obstet Gynaecol-144; 471-1982.

[15]. D Hills, G A Irwin, S Tuck et al distribution of placental grade in high risk gravidas. American Journal of Roentgenology Vol-143; Issue 5; 1011-1013.

[16]. Lucy Das, Umakant Satpathi, Jasmin Rath correlation betweek Ultrasonographic placental maturation study and pregnancy outcome, journal of medical science and clinical research. Vol 05; Issue 04 April 2017; 20516-20521.

[17]. Hill LM, Breckle R, Ragozzino MW et al grade 3 placentation: incidence and neonatal outcome. Obstet Gynaecol 1983; 61 (6): 728-732. 
[18]. Aggarwal V, Jain S placental grading and its correlation with foetal outcome. Journal of Obstetrics \& Gynaecology India 2000; 50: $1,59-62$.

[19]. Grannum PA, Berkowitz RL, Hobbins JC. The ultrasonic changes in the maturing placenta and there relation to foetal pulmonic maturity. AM J Obstet Gynaecol 1979; 133(8): 15-922.

[20]. Hopper KD, Kamppa GH, Bice P et al 1984: A revaluation of placental grading and its clinical significance. J ultrasound Med, 3; 261-266.

[21]. Mumol Nagwani, Pradeep Kumar Sharma, Urmila Singh et al. Two dimensional Ultrasonographic study of placental maturity and its correlation with gestational age and maternal parameters. Indian Journal of Clinical anatomy and Physiology 2015; 2 (3): 148153. 